\title{
DILATATION OF THE AORTA DUE TO GRANULOMATOUS (GIANT-CELL) AORTITIS
}

\author{
BY \\ J. V. O. REID \\ From the Pathological Laboratory, Radcliffe Infirmary, Oxford
}

Received March 3, 1956

Syphilis is generally considered to be the most frequent cause of gross aortic dilatation, but there are a number of other causes of this condition, and this paper draws attention to the occurrence of aortic dilatation in association with granulomatous (giant-cell) arteritis.

In syphilis the dilatation occurs in the ascending part and arch of the aorta. The aorta is dilated proximal and distal to a coarctation. In the presence of aortic valvular disease the ascending part may widen. In hypertension widening of the ascending part and arch may occur, though never to any great extent. Cystic medial necrosis with or without dissection may produce dilatation, particularly of the ascending aorta, and sometimes this becomes aneurysmal (Erdheim, 1929). Arteriosclerotic aneurysmal dilatation of these parts has been described. Ruffin et al. (1941) have reported three cases of a condition they call senile ectasia of the aorta, in which the ascending aorta is dilated in the absence of atherosclerosis.

Granulomatous aortitis, as a further cause of aortic dilatation, is less commonly recognized, although it has been shown repeatedly that "giant-cell" temporal arteritis is a generalized disease of large arteries (Cooke et al., 1946; Harrison, 1947). The particular liability of the aorta is shown by the observation that in every reported case of cranial arteritis where the aorta has been adequately examined microscopically, characteristic changes have been found. These cases, together with those having aortitis without cranial arteritis, have been enumerated by Cardell and Hanley (1951). Their list does not mention Sproul's case (1942) as having aortitis. Further examples were summarized by Heptinstall et al. (1954). Cases that should now be added are those of Magarey (1950), Rywlin and Kuschner (1953), and possibly those of Harbitz (1926), Shennan (1934) (Case 3), and Weber (1950). In all, twenty-one instances excluding the three possible ones, have been reported in which the aorta has been examined microscopically, and in all there has been an aortitis. The temporal artery was not involved in every case.

Dilatation of the aorta due to this condition has been reported before (Sproul and Hawthorne, 1937; Cooke et al., 1946; Weber, 1950). The aorta of Shennan's Case 3 (1934) had histological features suggestive of granulomatous aortitis; it was dilated in its ascending part. As regards other arteries, one of Gilmour's patients (1941) with granulomatous aortitis had an aneurysm of a subclavian artery. Dick and Freeman (1940) reported a case with a radiological appearance of innominate artery expansion, while Harrison et al. (1955) have described one with saccular aneurysms of large arteries.

In this paper four further examples of aortic dilatation due to giant-cell aortitis are reported.

\section{CASE Histories}

Case 1. A farmer, aged 65, had had rheumatic fever and paratyphoid fever in childhood, and pleurisy at the age of 35. Early in 1954 he had muscular pains in the arms, legs, and shoulders. In May of that year he developed œdema, ascites, and attacks of cardiac asthma. He was said to be hypertensive. From this episode he recovered with rest in bed and digitalis. Severe occipital headaches occurred in August, 1955 , seeming to be located in the scalp. Two days before admission on $1 / 10 / 55$, he began to have loss of vision and ocular pain.

Examination. A well-looking intelligent man. Blood pressure 175/100. Cardiac apex beat at the nipple line. Presystolic gallop rhythm present. On retinoscopy slight bilateral blurring of disc margins; the left upper quadrants of both visual fields alone were preserved. He was tender over the right occipital 
artery; the temporal pulses were absent, but these arteries were not tender. Moderate changes of rheumatoid arthritis were present in all joints of the limbs. E.S.R.: $135 \mathrm{~mm}$. in one hour. X-ray of the skull showed no abnormality. Chest X-ray showed enlargement of the left ventricle with widening of the ascending aorta (Fig. 1). Rose's differential agglutination test: weak positive (differential titre 16). A lumbar puncture revealed normal pressure and cerebrospinal fluid.

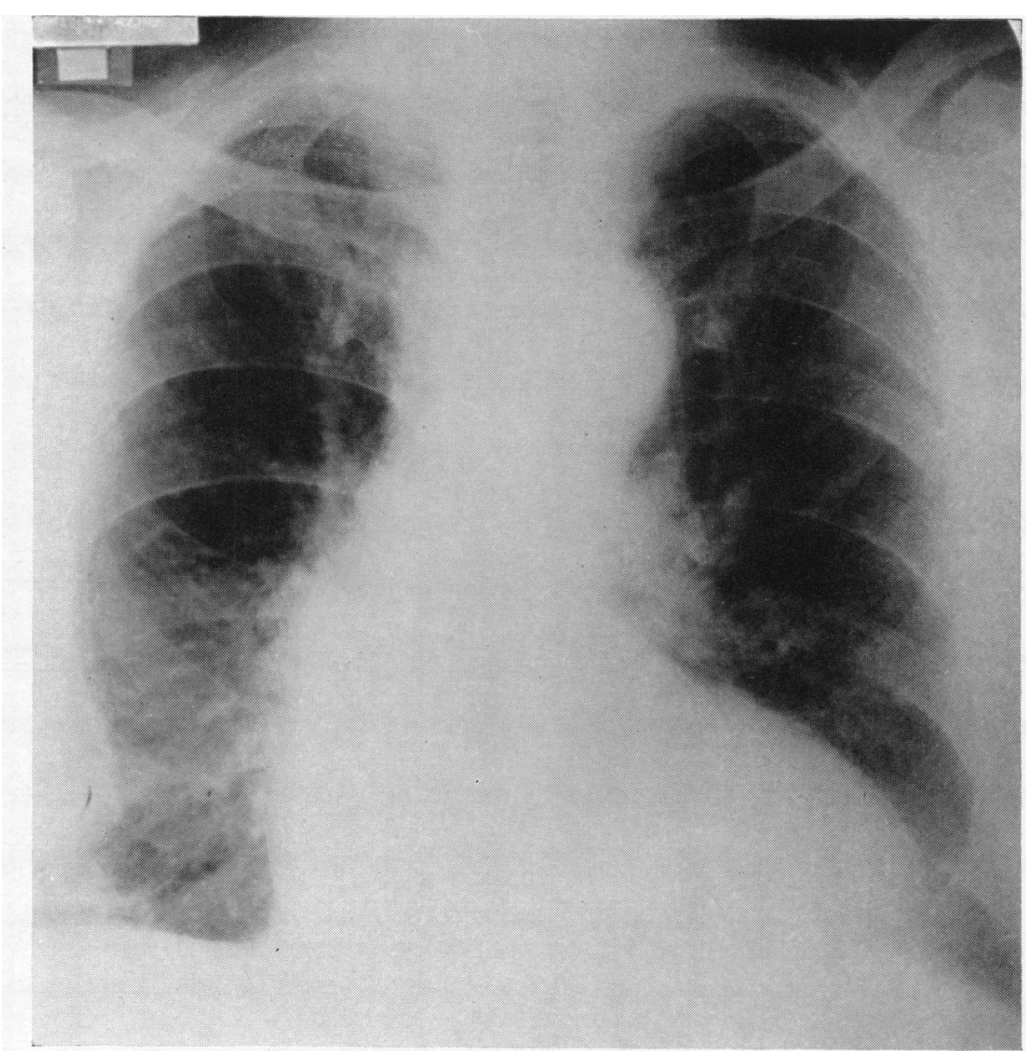

FIG. 1.-Case 1. X-ray, showing the dilatation of the ascending aorta, which was not as much in this case as in the others.

Progress. A diagnosis of cranial arteritis was made and he was treated with cortisone. All vision rapidly disappeared after admission. Two weeks after admission he complained of severe chest pain, and a pericardial friction rub became audible. An electrocardiogram showed left axis deviation, digitalis effect, and almost certain underlying ischæmic heart disease; there was no sign of cardiac infarction. His condition worsened, and he died three weeks after admission.

Post-mortem examination (P.M. 709/55). Rheumatoid arthritis of joints of hands and wrists, with mild changes in larger joints. Cardiovascular system. Hæmorrhagic pericarditis, the cavity containing $150 \mathrm{ml}$. of bloody fluid. Both ventricles were dilated and their walls somewhat hypertrophied. Mitral cusps and chordæ were thick and opaque, the valve admitting three fingers. Diffuse fibrosis of the myocardium was present and the coronary arteries were atheromatous. The aorta was dilated in its ascending part; no measurements were taken but the size was quite conspicuous; there was calcified atheroma of the abdominal part. No macroscopic abnormality was found in any of the larger or smaller arteries.

Microscopical findings. Granulomatous aortitis most severe in the apex of the arch and in the descending part in the thorax. Arteritis of the coronary, internal carotid, ciliary, ophthalmic, and femoral arteries. Hæmorrhagic pericarditis with very little inflammatory cell infiltrate. Fairly severe myocardial fibrosis, both diffuse and perivascular. The lesion in this patient was not as severe histologically, nor the dilatation of the aorta as great, as in the other cases. 
Case 2. A farm labourer, aged 71, gave no significant past history. In April, 1946, he began to have occipital headaches, and in July of that year hæmaturia, for which he was referred for investigation.

Examination. A well-nourished man. Blood pressure 140/90. The temporal and brachial arteries were very tortuous. Wassermann and Kahn tests negative. An X-ray of the skull was normal. X-rays of the chest showed emphysematous lungs and calcification of aortic arch. E.S.R. $118 \mathrm{~mm}$. in one hour. He was referred to Mr. J. Pennybacker, who considered the headaches to be due to cranial arteritis. By October, 1946, the headaches were considerably improved and soon disappeared. At this time he was admitted to hospital. Subsequent findings were absence of pulsation in the left leg at or below the knee, and in the right dorsalis pedis artery. The left plantar reflex was extensor, but there were no other neurological signs. E.S.R. $55 \mathrm{~mm}$. in one hour. White cell count $9000 / \mathrm{c} . \mathrm{mm}$. Lumbar puncture: normal pressure and fluid; Wassermann reaction negative. Cystoscopy showed a papilloma of the bladder which was treated by repeated diathermy.

Progress. Hæmaturia continued and in June, 1947, at further cystoscopy the lesion appeared malignant. It finally caused acute retention of urine, and the patient died in January, 1948.

Post-mortem examination. (P.M. 28/48). A wasted old man. There was atrophic emphysema of the lungs. The carcinoma of the bladder had spread extensively in the pelvis, and the kidneys showed hydronephrosis and chronic pyelonephritis. Cardiovascular system. Right ventricle dilated. Valves normal. The aorta was dilated throughout its thoracic part, with intimal irregularity suggestive of syphilitic aortitis. Coronary arteries atheromatous.

Microscopical findings. The tumour was a transitional-cell carcinoma. Granulomatous aortitis was present with much atheroma.

Case 3. A widow, aged 70 , had had acute rheumatism at the age of 12 , and the heart was said to be affected ever since. During 1952 she began to have pain in her head, on the right side, and in the right ear. On 10/6/54 there was sudden onset of deadness in the left leg, for which she was admitted.

Examination. A thin old woman. Blood pressure 210/75. Auricular fibrillation. There were mitral systolic and diastolic murmurs. The left femoral pulse was absent and the left leg was cold and mottled. Mild rheumatoid arthritis in the hands. E.S.R. $11 \mathrm{~mm}$. in one hour. White blood count $14,000 / \mathrm{c} . \mathrm{mm}$. Electrocardiogram: auricular fibrillation. An X-ray showed calcification of the aortic arch, and a cardiac configuration of mitral stenosis, but no hypoplasia of aorta; if anything there was slight dilatation.

Progress. The patient was treated for the incipient gangrene of the leg. Three weeks after admission she had a sudden right hemiplegia with aphasia, from which she did not recover.

Post-mortem examination (P.M. 413/54). The body of an old woman with swelling and discoloration of the left leg below the mid-thigh. Cardiovascular system. Dilatation of the left atrium and right ventricle. No antemortem thrombus in the atria or their appendages. Foramen ovale closed. The mitral valve had thick calcified cusps rolled down into the ventricle and admitting one finger only. The aortic cusps were normal and the valve supported a column of water. The myocardium of the left ventricle was diffusely fibrotic, and there was coronary atheroma. Aorta. Some calcification throughout, including the ascending part. This was conspicuously widened, quite out of keeping with an effect of hypertension and unexpected in view of the mitral stenosis. Thrombus in the abdominal aorta adherent to an atheromatous plaque. Both common iliac arteries and the left internal iliac were thrombosed. The common carotids, and the internal carotids as far as $4 \mathrm{~cm}$. beyond the bulbs, were normal. Old wedge infarct of the spleen. Benign nephrosclerosis with two small infarcts in each kidney. The left middle cerebral artery was thrombosed and there was softening of a corresponding area of the brain.

Microscopical findings. Granulomatous aortitis (Fig. 2) and arteritis affecting the femoral and iliac arteries. The carotid arteries were not examined. The middle cerebral artery showed atheroma at a point distal to the thrombus; no sections were taken through the attached thrombus itself. The other findings confirmed the macroscopic appearances.

Case 4. A woman, aged 81, was said to have had indigestion and kidney trouble for years. Three days before death she had a hæmatemesis and this recurred on the day of admission. She died on being taken into the admission room.

Post-mortem examination (P.M. 1/55). The body of an obese old woman, with anæmia of all organs. There was a large chronic duodenal ulcer with a bleeding point in its base. The intestine was full of blood and there was much inhaled blood. The liver looked normal. The kidneys had finely granular surfaces without much scarring on the cut surfaces. Cardiovascular system. The pericardium was adherent by fairly easily broken fibrous adhesions. The right ventricle was dilated. The left ventricular myocardium 


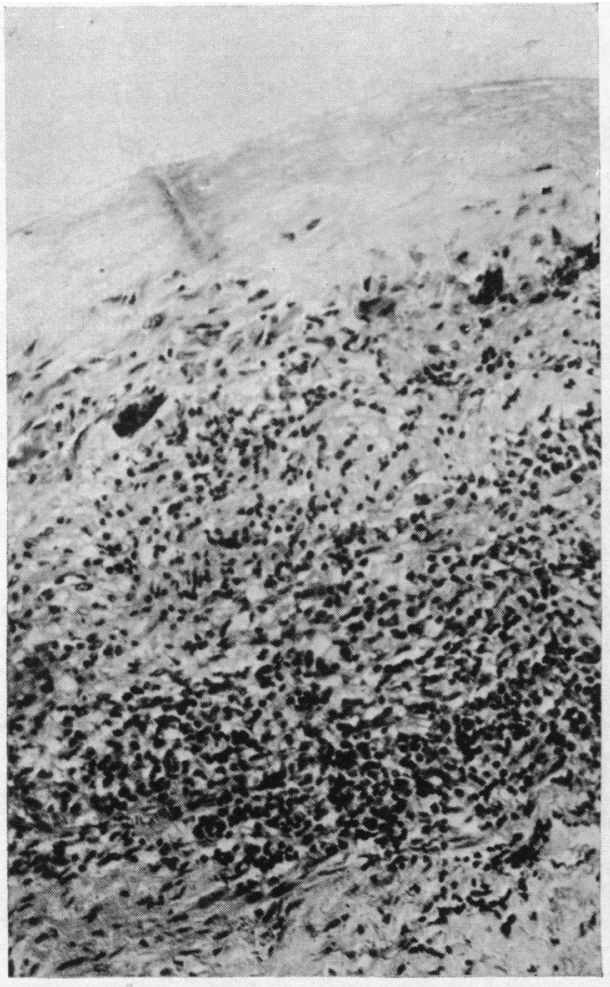

FIG. 2. Aorta of Case 3. A high-power view shows the cellular inflammatory infiltrate, in which four giant-cells lie along the site of the internal elastic lamina, and the media is almost entirely replaced. $(\times 200)$.

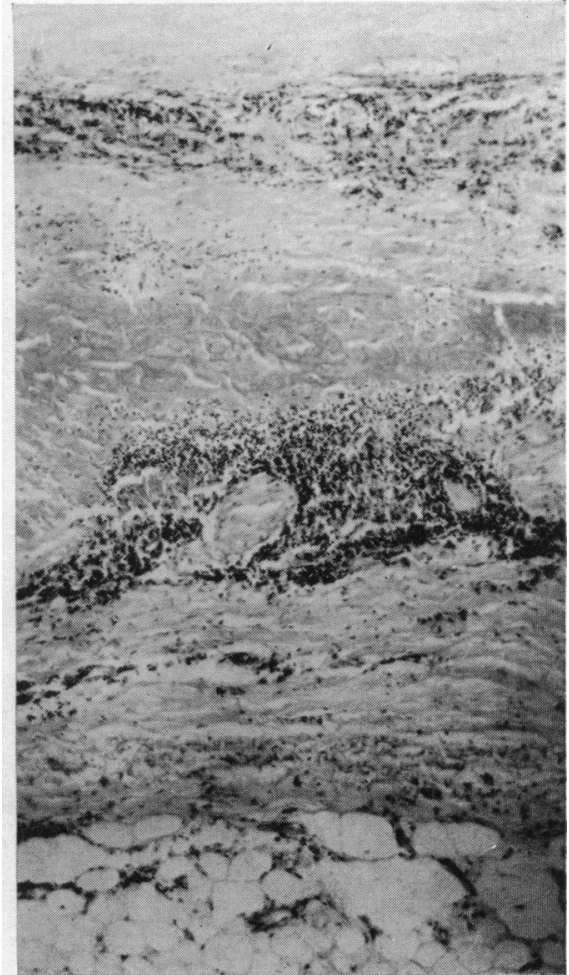

FIG. 3.-Aorta of Case 4. There are two bands of inflammatory tissue, at the outer and inner parts of the media. The inner band replaces the internal elastic lamina, and the media between the bands is infarcted. $(\times 100)$.

was scarred anteriorly. The valves and aortic ring were normal. The coronary arteries had normal ostia and mild general atheroma. Aorta. Much dilatation of the ascending aorta and arch, greater still in the upper part of the descending aorta, where it formed a fusiform aneurysmal expansion, but decreasing from there downwards. The intima was puckered in the ascending limb with star formation; there was extensive atheroma of the arch overlying similar scars. There was a large flat clot lying in the aneurysmal expansion of the arch beyond the origin of the three great vessels; its length was $10 \mathrm{~cm}$.

Microscopical examination. Benign nephrosclerosis. The aorta showed a severe granulomatous aortitis in an active cellular stage (Fig. 3). Miliary granulomata not of classical sarcoid type in the lungs and liver. This case differs from the others in the presence of these granulomatous lesions.

\section{Discussion}

In none of these cases was the aortic dilatation ascribable to the hypertension, where recorded, or to the amount of left ventricular hypertrophy revealed at necropsy examination.

In all of these four cases the histological picture was unlike that of syphilis and like that of previously described cases of granulomatous aortitis. A fifth case with an aneurysmal dilatation of the ascending aorta has not been included because of lack of supporting evidence, but in it also the histological picture of the aorta was quite unlike syphilitic aortitis. The microscopical appearances of the condition will be described in more detail elsewhere. In brief, the essential change is an inflammatory cell infiltration of the media, with some tendency to form into bands but not favouring any part of the media more than another (Fig. 2). The cells are plasma cells, lymphocytes, and larger mononuclear cells. Giant cells are usually present and may be numerous, but may on the other hand be very difficult to find. This applies to cases with known temporal arteritis as well 
as to the cases without. The infiltration is usually diffuse, but may collect into foci with normallooking media between them. There is destruction of the muscular and elastic elements of the media, particularly at the foci. These later scar and the inflammatory cells disappear. There is a tendency for bands of media to undergo an infarction-like process (Fig. 3). The mucoid change described in temporal arteritis is often present. Formation in the media of new capillaries is normally slight and is always much less in relation to the amount of inflammatory change than it is in syphilitic aortitis.

The intima is affected only by atheroma. The adventitia invariably shows some lymphocytic infiltration in the loose tissue or around vessels. It is sclerotic in older cases. Small arteries and arterioles in the adventitia show no endarteritis.

The difference from the syphilitic lesion lies in the presence of diffuse inflammation, its tendency to a band-like distribution, the paucity of new vessels, its exuberance in relation to other changes and in the absence of endarteritis of the vasæ or of characteristic microgummata. The fact that the aorta is affected in granulomatous aortitis may be recognized in life in a patient with temporal arteritis, not only by the dilatation of the aorta but also by its calcification. Where there is calcification without dilatation it is, of course, impossible to be absolutely sure; but the likelihood that an aortitis is responsible must be very great because of the high incidence, described above, in cases where the aorta has been examined microscopically.

Most cases of granulomatous arteritis are recognized because they have temporal or ophthalmic arteritis. Some (Rywlin and Kuschner, 1953; Finlayson and Robinson, 1955, Case 3) suffer gangrene of a leg due to thrombosis of its arteries. Histological examination of the artery in the amputated limb may then reveal the diagnosis. Thrombosis of the common or internal carotid arteries is a further feature in published cases (Gilmour, 1941; Harbitz, 1926; Ritama, 1951; McMillan, 1950), and at necropsy carotid involvement has nearly the same high incidence as the aortitis. For this reason granulomatous arteritis should be thought of in patients with this presentation. Here again, X-ray examination of the aorta may help, and a high E.S.R. corroborate.

\section{SUMMARY}

Case reports of four patients have been given together with records of the findings at necropsy. Aortic dilatation due to granulomatous (giant-cell) aortitis was found in each instance. Only two of the cases had clear histories of cranial arteritis.

Granulomatous aortitis must be considered when there is arteritis elsewhere, when there is dilatation of the ascending part or arch of the aorta, and in a variety of other presenting circumstances. It is likely that studies, particularly follow-up of patients with temporal arteritis, may reveal further cases.

I am grateful to Dr. F. G. Hobson, Dr. A. M. Cooke, and Dr. P. C. Mallam for permission to publish these cases. I am indebted to Dr. A. H. T. Robb-Smith for criticism and advice, and to Dr. F. H. Kemp for radiological interpretations.

\section{REFERENCES}

Cardell, B. S., and Hanley, T. (1951). J. Path. Bact., 63, 587.

Cooke, W. T., Cloake, P. C. P., Govan, A. D. T., and Colbeck, J. C. (1946). Quart. J. Med., 15, 47.

Dick, G. F., and Freeman, G. (1940). J. Amer. med. Ass., 114, 645.

Erdheim, J. (1929). Virchow Arch. Path. Anat., 273, 454.

Finlayson, R., and Robinson, J. O. (1955). Brit. med. J., 2, 21595.

Gilmour, J. R. (1941). J. Path. Bact., 53, 263.

Harbitz, R. (1926). Arch. Path., 1, 499.

Harrison, C. V. (1947). J. Clin. Path., 1, 197.

Harrison, R. J., Harrison, C. V., and Kopelman, H. (1955). Brit. med., J. 2, 1593.

Heptinstall, R. H., Porter, K. A., and Barkley, H. (1954). J. Path. Bact., 67, 507.

Magarey, F. R. (1950). J. Path. Bact., 62, 445.

McMillan, G. C. (1950). Arch. Path., 49, 63.

Ritama, V. (1951). Ann. Med. intern. Fenn., 40, 63.

Ruffin, M. de G., Castleman, B., and White, P. D. (1941). Amer. Heart J., 22, 458.

Rywlin, A., and Kuschner, H. (1953). Presse Méd., 61, 250.

Shennan, T. (1934). Med. Res. Council Sp. Report No. 193, London.

Sproul, E. E. (1942). N.Y. State J. Med., 42, 345.

, and Hawthorne, J. J. (1937). Amer. J. Path., 13, 311.

Weber, J. W. (1950). Frank. Zeit. Path., 61, 586. 